\title{
The effects of inspiratory muscle training on plasma interleukin-6 concentration during cycling exercise and a volitional mimic of the
} exercise hyperpnea

\author{
Dean E. Mills, ${ }^{1}$ Michael A. Johnson, ${ }^{1}$ Martin J. McPhilimey, ${ }^{1}$ Neil C. Williams, ${ }^{1}$ Javier T. Gonzalez, ${ }^{2}$ \\ Yvonne A. Barnett, ${ }^{1}$ and Graham R. Sharpe ${ }^{1}$ \\ ${ }^{1}$ Sport, Health and Performance Enhancement (SHAPE) Research Group, School of Science and Technology, Nottingham \\ Trent University, Nottingham, United Kingdom; and ${ }^{2}$ School of Life Sciences, Northumbria University, Newcastle upon Tyne, \\ United Kingdom
}

Submitted 1 March 2013; accepted in final form 24 July 2013

\begin{abstract}
Mills DE, Johnson MA, McPhilimey MJ, Williams NC, Gonzalez JT, Barnett YA, Sharpe GR. The effects of inspiratory muscle training on plasma interleukin-6 concentration during cycling exercise and a volitional mimic of the exercise hyperpnea. $J$ Appl Physiol 115: 1163-1172, 2013. First published July 25, 2013; doi:10.1152/japplphysiol.00272.2013.-It is unknown whether the respiratory muscles contribute to exercise-induced increases in plasma interleukin-6 (IL-6) concentration, if this is related to diaphragm fatigue, and whether inspiratory muscle training (IMT) attenuates the plasma IL-6 response to whole body exercise and/or a volitional mimic of the exercise hyperpnea. Twelve healthy males were divided equally into an IMT or placebo (PLA) group, and before and after a 6-wk intervention they undertook, on separate days, $1 \mathrm{~h}$ of 1 ) passive rest, 2) cycling exercise at estimated maximal lactate steady state power (EX), and 3) volitional hyperpnea at rest, which mimicked the breathing and respiratory muscle recruitment patterns achieved during EX (HYPEX). Plasma IL-6 concentration remained unchanged during passive rest. The plasma IL-6 response to EX was reduced following IMT (main effect of intervention, $P=0.039)$ but not PLA $(P=$ 0.272). Plasma IL-6 concentration increased during HYPEX (main effect of time, $P<0.01$ ) and was unchanged postintervention. There was no evidence of diaphragm fatigue (measured by phrenic nerve stimulation) following each trial. In conclusion, plasma IL-6 concentration is increased during EX and HYPEX and this occurred in the absence of diaphragm fatigue. Furthermore, IMT reduced the plasma IL-6 response to EX but not HYPEX. These findings suggest that the respiratory muscles contribute to exercise-induced increases in plasma IL- 6 concentration in the absence of diaphragm fatigue and that IMT can reduce the magnitude of the response to exercise but not a volitional mimic of the exercise hyperpnea.
\end{abstract}

interleukin-6; exercise; respiratory muscles; diaphragm fatigue; inspiratory muscle training

INCREASED RESPIRATORY MUSCLE work is encountered during strenuous whole body exercise, asthma attacks, and exacerbations of chronic obstructive pulmonary disease (COPD) and when sufficiently strenuous can result in diaphragmatic fatigue. These scenarios can result in systemic inflammation and oxidative stress due to enhanced production of inflammatory cytokines and reactive oxygen species (ROS), respectively (35, $50,68)$.

During whole body exercise the myokine interleukin-6 (IL-6) demonstrates the largest increase (50), with contracting

\footnotetext{
Address for reprint requests and other correspondence: D. Mills, School of Science and Technology, Nottingham Trent University, Nottingham, NG11 8NS, UK (e-mail: dean.mills@ntu.ac.uk).
}

skeletal muscle accounting for most (but not all) of the exercise-induced increase in plasma IL-6 concentration (58). IL-6 acts to stimulate lipolysis (67), hepatic glucose output (20), and glucose uptake in the contracting myocytes (10). However, not all skeletal muscles release the same amount of IL-6 during whole body exercise. When expressed relative to the size of the muscle group used, the arm muscles release greater amounts of IL-6 than leg muscles, which may be due to differences in fiber-type composition and vascular supply (26).

The respiratory muscles also exhibit different fiber-type composition and vascular supply compared with leg muscles (48), but given their relatively small mass [ 960 g (23)] it may seem unlikely that they contribute to exercise-induced increases in plasma IL-6 concentration. However, Vassilakopoulos et al. (64) reported a $120 \%$ increase in plasma IL-6 concentration in young and healthy humans following inspiratory resistive loading (IRL) at $75 \%$ maximal inspiratory mouth pressure (MIP). The increase in plasma IL- 6 concentration was attributed to increased rates of IL-6 release from the inspiratory muscles, which is supported by the observation of increased IL-6 mRNA and protein expression in the diaphragm of rats exposed to IRL $(53,54,62)$. Although these findings have clinical relevance to those with asthma and obstructive lung disease, they cannot be generalized to healthy humans performing whole body exercise as, compared with IRL, spontaneous exercise hyperpnea elicits different breathing and respiratory muscle recruitment patterns $(14,15,18)$.

Vassilakopoulos et al. (63, 64) also suggested that the increase in plasma IL-6 concentration (and other cytokines) may be due to inspiratory/diaphragm muscle fiber injury/ fatigue since IRL was performed until task failure, which occurred after $54 \pm 10 \mathrm{~min}$. However, inspiratory muscle fatigue was assessed using a volitional measure of MIP, which may decline following IRL until task failure due to a decrease in central drive globally rather than diaphragm fatigue $(2,44)$. The question of whether respiratory muscles release IL-6 during exercise and if this is related to diaphragm fatigue may be better addressed using volitional hyperpnea at rest. In this model, validity is improved by mimicking the breathing and respiratory muscle recruitment patterns experienced during whole body exercise $(4,36)$. The presence of diaphragm fatigue can also be measured more objectively by using bilateral phrenic nerve stimulation (2).

Recent evidence suggests that the plasma IL-6 response to exercise is attenuated following whole body resistance (30) and endurance $(1,16,70)$ training. Increases in basal levels of IL-6 
receptor $\alpha(1,34)$ or an increase in antioxidant enzymes (70) may explain such reductions. Alternatively, a strong stimulus for IL-6 production by skeletal muscle fibers is muscle glycogen depletion $(34,56)$, which is attenuated in trained muscle $(16,22)$ secondary to training-induced increases in mitochondrial density (27). Inspiratory muscle training (IMT) may elicit similar morphological adaptations in the inspiratory muscles $(7-9,51)$ and thus also attenuate the plasma IL-6 response to whole body exercise and/or volitional hyperpnea.

Therefore the aim of this study was to examine whether the respiratory muscles contribute to exercise-induced increases in plasma IL-6 concentration, if this is related to diaphragm fatigue, and whether IMT attenuates the plasma IL- 6 response to whole body exercise and/or a volitional mimic of the exercise hyperpnea.

\section{METHODS}

Participants. Twelve nonsmoking recreationally active males provided written, informed consent to participate in the study, which was approved by the local ethics committee. A self-reporting medical questionnaire confirmed that participants were free from illness and injury and not taking any medication and/or antioxidant supplements during the study. Each participant completed a 24-h diet record prior to their first trial, which was then replicated prior to all subsequent trials. Throughout the study, participants were instructed to adhere to their habitual training regimen and not to engage in any strenuous exercise the day preceding and the day of a trial. Participants arrived at the laboratory $4 \mathrm{~h}$ postprandially, having abstained from alcohol and caffeine in the $24 \mathrm{~h}$ before testing.

Experimental design. Participants attended the laboratory on six separate occasions, before and after a 6-wk intervention (Fig. 1). Each laboratory visit was separated by $48 \mathrm{~h}$ and took place at the same time of day. During the first visit, participants were familiarized with all testing procedures and pulmonary function and MIP were measured. During the second visit participants performed a cycling lactate minimum test to estimate maximal lactate steady state power. The subsequent three experimental trials lasted $1 \mathrm{~h}$ and comprised 1) passive rest (PASSIVE), 2) cycling exercise at the participants lactate minimum power (EX), and 3) volitional hyperpnea at rest whereby participants mimicked the breathing and respiratory muscle recruitment patterns achieved during EX (HYPEX). Since EX had to precede HYPEX, the experimental trials were only partially randomized. Following the final trial, participants were randomly, and equally, divided into an IMT or placebo (PLA) group and completed the intervention. At least $48 \mathrm{~h}$ postintervention, participants repeated the lactate minimum test and experimental trials in the same order as preintervention. All trials were performed on an electromagnetically braked cycle ergometer (Excalibur Sport; Lode, Groningen, Netherlands).

Pulmonary function and maximal inspiratory mouth pressure. Pulmonary function was assessed according to published guidelines (46) using a pneumotachograph (Pneumotrac; Vitalograph, Buckinghamshire, UK) calibrated with a 3-liter syringe. A hand-held mouth pressure meter (MicroRPM; CareFusion, Hampshire, UK) measured MIP as an index of global inspiratory muscle strength. The mouthpiece assembly incorporated a $1 \mathrm{~mm}$ orifice to prevent glottic closure during inspiratory efforts. Maneuvers were performed while standing, initiated from residual volume, and sustained for at least $1 \mathrm{~s}$. Repeat efforts separated by $30 \mathrm{~s}$ were performed until three serial measures differed by no more than $10 \%$ or $10 \mathrm{cmH}_{2} \mathrm{O}$, whichever was smallest $(7,8,31)$. The highest value recorded was used for subsequent analysis.

Lactate minimum test. The lactate minimum test was performed following the procedures of Johnson et al. (32) who reported excellent agreement between lactate minimum and maximal lactate steady-state cycling powers (mean bias $\pm 95 \%$ limits of agreement: $2 \pm 22 \mathrm{~W}$ ). The test comprised three consecutive phases: 1) blood lactate concentration $\left(\left[\mathrm{La}^{-}\right]_{\mathrm{B}}\right)$ elevation phase comprising maximal incremental exercise, 2) $8 \mathrm{~min}$ recovery phase at $60 \mathrm{~W}$, and 3) incremental phase comprising five consecutive 4-min exercise stages at intensities of 45 , $50,55,60$, and $65 \%$ of the maximum power achieved during the lactate elevation phase. During the $\left[\mathrm{La}^{-}\right]_{\mathrm{B}}$ elevation phase, power output was increased by $10 \mathrm{~W}$ every $15 \mathrm{~s}$ to elicit exercise intolerance in $\sim 10 \mathrm{~min}$. The highest oxygen uptake recorded in any $30 \mathrm{~s}$ period defined peak oxygen uptake $\left(\mathrm{V}_{2}\right.$ peak $)$. During the incremental phase, blood samples were taken in the final seconds of each stage, and the lactate minimum power (i.e., estimated maximal lactate steady state power) was calculated as the nadir of a second-order polynomial fitting the $\left[\mathrm{La}^{-}\right]_{\mathrm{B}}$ against power data.

Experimental trials. During experimental trials the configuration of the cycle ergometer and the body position adopted by each participant were identical to those adopted during the lactate minimum test. Each trial was preceded by a 5-min rest period, and during PASSIVE participants remained seated on the cycle ergometer for the duration

Fig. 1. Schematic of experimental design.

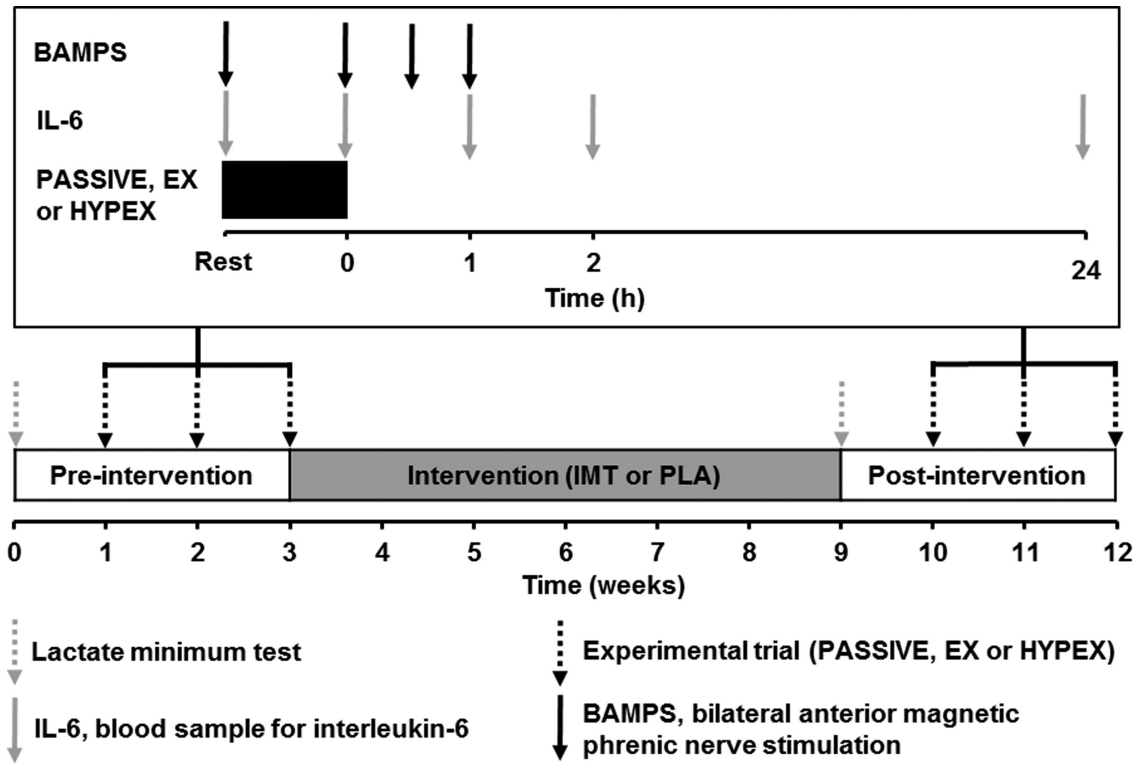


of the trial. During pre- and postintervention EX trials participants cycled at their preintervention lactate minimum power and each participant adopted the same cycling cadence during all trials. During HYPEX participants mimicked the breathing (tidal volume, $\mathrm{V}_{\mathrm{T}}$; breathing frequency, $f_{\mathrm{B}}$; and duty cycle, $\mathrm{T}_{\mathrm{I}} / \mathrm{T}_{\mathrm{TOT}}$ ) and respiratory muscle recruitment (peak transdiaphragmatic pressure, $\mathrm{P}_{\text {dipeak }}$ ) patterns attained during preintervention EX. These variables were ensemble averaged into six 10-min blocks from the EX data and targets were updated during the HYPEX trial. During the postintervention HYPEX trial, participants mimicked the breathing and respiratory muscle recruitment patterns performed during the preintervention HYPEX trial. An audio metronome paced $f_{\mathrm{B}}$ and $\mathrm{T}_{\mathrm{I}} / \mathrm{T}_{\mathrm{TOT}}$, and real-time visual feedback of $\mathrm{V}_{\mathrm{T}}$ and $\mathrm{P}_{\text {dipeak }}$ was provided throughout. The use of $\mathrm{P}_{\text {dipeak }}$ targets allowed us to more precisely control the mechanical work of breathing during volitional hyperpnea $(4,36)$. All experimental trials were performed in an environmental chamber (Design Environmental WIR52-20HS; Design Environmental, Gwent, UK) at $20^{\circ} \mathrm{C}$ and $90 \%$ relative humidity to minimize mucosal drying during HYPEX.

Flow, pulmonary gas exchange, and pressure measurements. During all trials, participants wore a facemask (model 7940; Hans Rudolph) connected to a pneumotachograph and ventilatory and pulmonary gas exchange responses were measured breath by breath (ZAN 600USB; Nspire Health, Oberthulba, Germany). During experimental trials a two-way nonrebreathing valve (model 2730; Hans Rudolph) was attached distally to the pneumotachograph and a $1.5 \mathrm{~m}$ length of wide-bore tubing was connected to the inspiratory port. During $\mathrm{HYPEX}, \mathrm{CO}_{2}$ was added into this tubing to increase $\mathrm{F}_{\mathrm{I}} \mathrm{CO}_{2}$ and thus retain end-tidal and, consequently, blood $\mathrm{PCO}_{2}$ at levels commensurate with rest $(9,33)$. On the expiratory port of the two-way valve a Fleisch no. 3 pneumotachograph was attached and connected to a differential pressure transducer $\left( \pm 2.5 \mathrm{cmH}_{2} \mathrm{O}\right)$ (TSD160A; BIOPAC Systems) and differential bridge amplifier (DA100C; BIOPAC Systems) to allow alignment of flow and pressure signals. Esophageal $\left(\mathrm{P}_{\mathrm{e}}\right)$ and gastric $\left(\mathrm{P}_{\mathrm{g}}\right)$ pressures were measured using two thin-walled $(\sim 0.6$ $\mathrm{mm}$ ) latex balloons sealed over a single polyethylene catheter (Nspire Health), which was attached to a differential pressure transducer ( \pm $400 \mathrm{cmH}_{2} \mathrm{O}$ ) (TSD104A; BIOPAC Systems) and differential bridge amplifier (DA100C; BIOPAC Systems). Pressure transducers were calibrated across the physiological range and pressure and flow (from the Fleisch pneumotachograph) signals were sampled at $200 \mathrm{~Hz}$ using an analog-digital converter and recorded using specific data acquisition software (Acqknowledge version 3.7.3; BIOPAC systems). The balloon catheter was initially positioned in the stomach following local anesthesia of the nasal mucosa and posterior pharynx using $2 \%$ lidocaine (Instillagel; Farco-Pharma, Cologne, Germany). Following a Valsalva maneuver, the esophageal and gastric balloons were evacuated of air using a glass syringe and subsequently filled with 1 and 2 $\mathrm{ml}$ of air, respectively. The catheter was then withdrawn until, during repeated sniffs, $\mathrm{P}_{\mathrm{e}}$ became negative. Subsequently, the catheter was withdrawn a further $10 \mathrm{~cm}$. During the first experimental trial the distance from the tip of the nares to the most distal point of the catheter was recorded and replicated in subsequent trials. Transdiaphragmatic pressure $\left(\mathrm{P}_{\mathrm{di}}\right)$ was calculated by subtracting $\mathrm{P}_{\mathrm{e}}$ from $\mathrm{P}_{\mathrm{g}}$. $\mathrm{P}_{\mathrm{di}}$ and $\mathrm{P}_{\mathrm{e}}$ were integrated over the period of inspiratory flow and multiplied by $f_{\mathrm{B}}$ and labeled the diaphragm pressure-time product $\left(\mathrm{PTP}_{\mathrm{di}}\right)$ and the inspiratory muscle pressure-time product $\left(\mathrm{PTP}_{\mathrm{e}}\right)$, respectively. Nonphysiological flows and pressures that resulted from swallowing, coughing, and breath holding were identified by visual inspection and removed. Breathing mechanics data were ensemble averaged into six 10-min blocks and used for subsequent analysis.

Bilateral anterior magnetic phrenic nerve stimulation. Bilateral anterior magnetic phrenic nerve stimulation (BAMPS) (47) was applied using two double $25 \mathrm{~mm}$ coils connected to two Magstim $200^{2}$ stimulators (Magstim, Dyfed, UK) that were triggered simultaneously. Participants initially rested for $20 \mathrm{~min}$ to minimize postactivation potentiation $(41,69)$. The location of each phrenic nerve was then identified by stimulating the area at the posterior border of the sternomastoid muscle at the level of the cricoid cartilage and determining the area associated with the largest peak to peak amplitude of transdiaphragmatic twitch pressure $\left(\mathrm{P}_{\mathrm{ditw}}\right)$. This location was marked with indelible ink and used for subsequent stimulations. During stimulations, participants were seated upright with no abdominal binding $(37,42)$, wore a noseclip, and prior to stimulation were instructed to hold at functional residual capacity $(28,55)$, which was inferred from visual feedback of $\mathrm{P}_{\mathrm{e}}$.

Skin surface electromyography (EMG) of the right costal diaphragm was recorded using bipolar surface electrodes (self-adhesive, $\mathrm{Ag}-\mathrm{AgCl}, 10 \mathrm{~mm}$ recording surface diameter; Unilect, Worcestershire, UK) placed on the sixth and eighth intercostal spaces in the anterior axillary line (24). Electrodes were positioned to optimize peak to peak amplitude of M-wave responses. EMG signals were passed through a differential amplifier (1902 Mk IV; Cambridge Electronic Design, Cambridge, UK), sampled at 2,000 $\mathrm{Hz}$ using an analog-digital converter (Micro 1401; Cambridge Electronic Design) and recorded using specific data acquisition software (Spike 2 version 5.12; Cambridge Electronic Design).

To determine supramaximal phrenic nerve stimulation, three single twitches were obtained every $30 \mathrm{~s}$ at intensities of 50, 60, 70, 80, 85, 90,95 , and $100 \%$ of maximal stimulator output. A plateau in $\mathrm{P}_{\text {ditw }}$ and M-wave responses with increasing stimulation intensities indicated maximum depolarization of the phrenic nerves. The technical considerations regarding supramaximal stimulation have been described previously $(17,59)$. $\mathrm{P}_{\text {ditw }}$ was assessed every $30 \mathrm{~s}$ using eight single stimuli at $100 \%$ of maximal stimulator output. $\mathrm{P}_{\text {ditw }}$ was measured at baseline and within 15 (<15 $\mathrm{min}$ ), 35 (<35 min), and 60 (<60 min) min after each experimental trial. Additionally, $\mathrm{P}_{\mathrm{ditw}}$ at each measurement point was followed by the assessment of the potentiated $\mathrm{P}_{\text {ditw }}$ response. Participants performed a 3-s maximal Müeller maneuver and $\sim 5 \mathrm{~s}$ later a single stimuli was delivered. This procedure was repeated six times with each measure separated by $30 \mathrm{~s}$. A potentiated $\mathrm{P}_{\text {ditw }}$ has greater sensitivity to fatigue especially when the degree of fatigue is small $(39,40)$. The average of the median three individual $\mathrm{P}_{\text {ditw }}$ responses were used for analysis. Diaphragm fatigue was defined as a $>15 \%$ reduction in $\mathrm{P}_{\text {ditw }}$ compared with the baseline value (38).

Blood analyses and additional measurements. Arterialized venous blood was sampled from a dorsal hand vein via an indwelling 21-G cannula (45). Arterialization was ensured by immersing the hand in water at $40^{\circ} \mathrm{C}$ for $10 \mathrm{~min}$ prior to cannulation and by warming the hand during trials using an infrared lamp. During the experimental trials blood samples were taken at rest, every $3 \mathrm{~min}$ for the initial 15 min, and every 5 min thereafter, and analyzed immediately for $\mathrm{PCO}_{2}$ and pH (ABL520; Radiometer, Copenhagen, Denmark), which were corrected for changes in rectal temperature (Squirrel 2020; Grant Instruments, Cambridge, UK). At rest and every 10 min during each trial $\left[\mathrm{La}^{-}\right]_{\mathrm{B}}$ was determined using an automated analyzer (Biosen C_line Sport; EKF Diagnostics, Barleben, Germany), and measurements were taken for cardiac frequency $\left(f_{\mathrm{C}}\right)$ using short-range telemetry (Polar S610; Polar, Kempele, Finland), estimated arterial oxygen saturation $\left(\mathrm{SpO}_{2}\right)$ using infrared fingertip pulse oximetry (Model 8600; Nonin), and rating of perceived exertion (RPE) for dyspnea and leg discomfort using Borg's modified CR10 scale (6). At rest, immediately after $(0 \mathrm{~h})$ and $1(+1 \mathrm{~h}), 2(+2 \mathrm{~h})$, and $24(+24 \mathrm{~h}) \mathrm{h}$ after each experimental trial, $5 \mathrm{ml}$ blood samples were taken for the measurement of plasma IL- 6 concentration. Blood was transferred into precooled tubes containing $1.6 \mathrm{mg} / \mathrm{ml}$ of $\mathrm{K}_{3} \mathrm{E}$ EDTA (SARSTEDT, Leicester, UK) and immediately centrifuged for $15 \mathrm{~min}$ at $1,000 \times g$ and $5^{\circ} \mathrm{C}$. The plasma supernatant was subsequently removed and stored at $-80^{\circ} \mathrm{C}$ until further analysis. Plasma IL- 6 concentrations were measured in duplicate using a commercial solid phase sandwich ELISA (Quantikine HS; R\&D Systems, Abingdon, UK). The assay has a detection limit of $0.039 \mathrm{pg} / \mathrm{ml}$. To minimize the effect of interassay variation, pre- and postintervention samples from both groups were measured during the same assay. The inter- and intra- 
assay coefficient of variation (CV) for plasma IL-6 concentration was $<10 \%$.

Inspiratory muscle training and placebo interventions. The intervention lasted 6 wk. The IMT group performed 30 consecutive dynamic inspiratory efforts twice daily using an inspiratory pressurethreshold device (POWERbreathe Classic series 1st generation; Gaiam, UK). The initial training load was 50\% MIP. Thereafter, participants periodically increased the load so that 30 maneuvers could only just be completed. Each inspiratory effort was initiated from residual volume and participants strove to maximize $\mathrm{V}_{\mathrm{T}}$. This regimen is known to be effective in eliciting an adaptive response $(7-9,52)$. The PLA group inhaled one puff twice daily from a sham metered dose inhaler (Vitalograph). The inhaler contained compressed air only but was promoted to the participants as delivering a novel drug that reduces breathing-induced inflammation. During the postintervention period the IMT and PLA groups performed their intervention 2 days/wk, which is sufficient to maintain improvements in inspiratory muscle function following IMT (52). These maintenance sessions were performed $48 \mathrm{~h}$ before and $48 \mathrm{~h}$ after experimental trials. All participants completed a training diary throughout the study to record adherence to the prescribed intervention and whole body training sessions.

Statistical analyses. Statistical analyses were performed using SPSS for Windows (IBM, Chicago, IL). Between- and within-group comparisons of baseline characteristics, including pulmonary function and MIP, were made using independent and paired $t$-tests, respectively. A three-way ANOVA was used to analyze the effects of "intervention" (pre- vs. post-"treatment") and "time" (10, 20, 30, 40, 50 , and $60 \mathrm{~min}$ for all physiological and perceptual variables; $0,+1$, +2 , and +24 h for plasma IL- 6 data; or baseline, $<15,<35$, and $<60$ min for $\mathrm{P}_{\text {ditw }}$ data) with a between-subject factor of "trial" (EX vs. HYPEX) for breathing and respiratory muscle recruitment pattern data, or "treatment" (IMT vs. PLA) for all other data. Intervention $\times$ treatment interaction effects and within-group changes were further explored by analyzing IMT and PLA groups separately using two-way repeated measures ANOVA. Reliability was assessed using a CV calculated from a pooled mean of both groups and all trials. Statistical significance was set at $P<0.05$. Results are presented as means $\pm \mathrm{SD}$.

\section{RESULTS}

Age (IMT vs. PLA: $27 \pm 7$ vs. $22 \pm 3$ yr), body mass $(80 \pm 6$ vs. $74 \pm 7 \mathrm{~kg})$, height $(181 \pm 5$ vs. $177 \pm 4 \mathrm{~cm})$, and $\dot{V}_{\text {O}_{2 p e a k}}\left(52 \pm 6.2\right.$ vs. $\left.47 \pm 5.7 \mathrm{ml} \cdot \mathrm{kg}^{-1} \cdot \mathrm{min}^{-1}\right)$ were not different between groups. Maximum power $(378 \pm 22$ vs. $336 \pm 23 \mathrm{~W})$ and lactate minimum power $(199 \pm 8$ vs. $170 \pm$ $19 \mathrm{~W})$ were higher $(P<0.01)$ in the IMT group compared with the PLA group. All other preintervention measurements were not different between groups. $\dot{\mathrm{V}}_{2 \text { peak }}$, maximum power, and lactate minimum power were unchanged after both IMT and PLA. In both groups all responses remained unchanged throughout PASSIVE trials (data not shown).

Pulmonary function and maximal inspiratory pressure. Preintervention pulmonary function (data not shown) and MIP were within normal limits. Compliance with the intervention was excellent in both IMT and PLA groups with $96 \pm 1$ and $93 \pm 1 \%$ of sessions completed, respectively. Pulmonary function was unchanged in both groups postintervention, whereas MIP increased from $168 \pm 49$ to $202 \pm 39 \mathrm{cmH}_{2} \mathrm{O}$ $(+24 \pm 16 \%)$ after IMT $(P<0.01)$. Inspection of training diaries revealed habitual whole-body training remained constant in both groups.

Breathing and respiratory muscle recruitment patterns. When performed separately for IMT and PLA groups, threeway ANOVA with repeated measures across intervention (prevs. posttreatment) and time (10, 20, 30, 40, 50, and $60 \mathrm{~min}$ ), with a between-subject factor of trial (EX vs. HYPEX), revealed no main effects of intervention or trial for breathing and

Table 1. Physiological and perceptual responses to EX and HYPEX trials for IMT and PLA groups

\begin{tabular}{|c|c|c|c|c|}
\hline & \multicolumn{2}{|c|}{ EX } & \multicolumn{2}{|c|}{ HYPEX } \\
\hline \multicolumn{5}{|l|}{ IMT } \\
\hline $\mathrm{V}_{\mathrm{T}}$, liters & $2.41 \pm 0.53$ & $2.40 \pm 0.53$ & $2.31 \pm 0.53$ & $2.31 \pm 0.53$ \\
\hline$f_{\mathrm{B}}$, breaths $/ \mathrm{min}$ & $36 \pm 9$ & $33 \pm 6$ & $35 \pm 9$ & $35 \pm 9$ \\
\hline $\mathrm{T}_{\mathrm{I}} / \mathrm{T}_{\mathrm{TOT}}$ & $0.47 \pm 0.01$ & $0.48 \pm 0.02$ & $0.49 \pm 0.04$ & $0.48 \pm 0.05$ \\
\hline$\left[\mathrm{La}^{-}\right]_{\mathrm{B}}, \mathrm{mmol} / \mathrm{l}$ & $4.21 \pm 1.88$ & $2.74 \pm 1.08$ & $0.84 \pm 0.14$ & $0.92 \pm 0.10$ \\
\hline$f_{\mathrm{C}}$, beats $/ \mathrm{min}$ & $163 \pm 15$ & $159 \pm 14$ & $68 \pm 9$ & $68 \pm 12$ \\
\hline $\mathrm{SpO}_{2}, \%$ & $95 \pm 1$ & $95 \pm 1$ & $99 \pm 1$ & $99 \pm 1$ \\
\hline RPE (dyspnea) & $3.9 \pm 1.7$ & $2.0 \pm 1.5$ & $2.8 \pm 1.6$ & $1.7 \pm 1.3$ \\
\hline RPE (leg) & $5.8 \pm 1.3$ & $5.2 \pm 1.2$ & $0.0 \pm 0.0$ & $0.0 \pm 0.0$ \\
\hline \multicolumn{5}{|l|}{ PLA } \\
\hline$\dot{\mathrm{V}}_{\mathrm{E}}$, liters/min & $61.6 \pm 14.5$ & $59.6 \pm 12.5$ & $58.2 \pm 13.4$ & $59.1 \pm 14.6$ \\
\hline $\mathrm{V}_{\mathrm{T}}$, liters & $1.77 \pm 0.34$ & $1.78 \pm 0.27$ & $1.69 \pm 0.36$ & $1.72 \pm 0.40$ \\
\hline $\mathrm{PCO}_{2}, \mathrm{mmHg}$ & $41.2 \pm 2.7$ & $41.1 \pm 2.6$ & $42.1 \pm 2.8$ & $42.5 \pm 3.2$ \\
\hline$f_{\mathrm{C}}$, beats $/ \mathrm{min}$ & $158 \pm 16$ & $153 \pm 14$ & $66 \pm 10$ & $63 \pm 7$ \\
\hline $\mathrm{SpO}_{2}, \%$ & $96 \pm 1$ & $96 \pm 1$ & $99 \pm 1$ & $99 \pm 1$ \\
\hline RPE (dyspnea) & $3.7 \pm 2.9$ & $3.2 \pm 4.4$ & $1.6 \pm 2.1$ & $1.3 \pm 1.7$ \\
\hline RPE (leg) & $5.1 \pm 2.7$ & $5.2 \pm 3.4$ & $0.0 \pm 0.0$ & $0.0 \pm 0.0$ \\
\hline
\end{tabular}

Values are mean $\pm \mathrm{SD} . \dot{\mathrm{V}}_{\mathrm{E}}$, minute ventilation; $\mathrm{V}_{\mathrm{T}}$, tidal volume; $f_{\mathrm{B}}$, breathing frequency; $\mathrm{T}_{\mathrm{I}} / \mathrm{T}_{\mathrm{TOT}}$, duty cycle; $\left[\mathrm{La}^{-}\right]_{\mathrm{B}}$, blood lactate concentration; PCO partial pressure of carbon dioxide; $f_{\mathrm{C}}$, cardiac frequency; $\mathrm{SpO}_{2}$, arterial oxygen saturation; RPE, rating of perceived exertion. See text for description of analyses. 


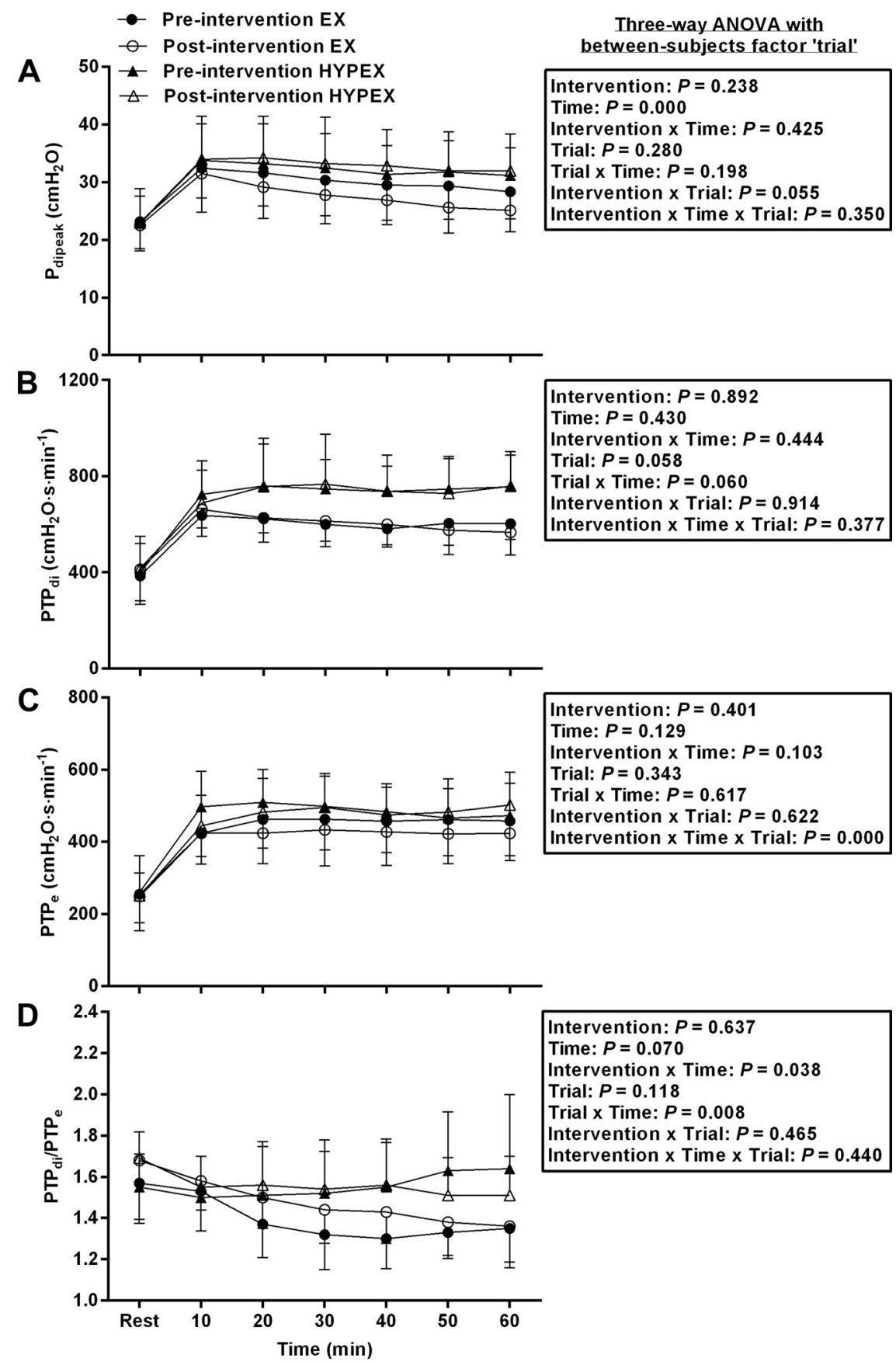

Fig. 2. Peak transdiaphragmatic pressure $\left(\mathrm{P}_{\text {dipeak }} ; A\right)$, diaphragm pressure-time product $\left(\mathrm{PTP}_{\mathrm{di}} ; B\right)$, inspiratory muscle pressure-time product $\left(\mathrm{PTP}_{\mathrm{e}} ; C\right)$, and the relative contribution of diaphragm to the inspiratory muscle pressure-time product $\left(\mathrm{PTP}_{\mathrm{di}} / \mathrm{PTP}_{\mathrm{e}} ; D\right)$ for the IMT group. Values are means $\pm \mathrm{SD}$.

respiratory muscle recruitment patterns. This shows that the breathing and respiratory muscle recruitment patterns observed during EX were successfully mimicked in HYPEX and that these factors were the same before and after IMT and PLA (Table 1 and Figs. 2 and 3). The only exception was that in the IMT group $\mathrm{PTP}_{\mathrm{di}} / \mathrm{PTP}_{\mathrm{e}}$ changed differently over time between the two trials (trial $\times$ time interaction, $P=0.008$ ) and in the PLA group PTP $_{\text {di }}$ changed differently over time between the two trials (trial $\times$ time interaction, $P=0.026$ ) (Table 1 and Figs. 2 and 3). The intertrial $\mathrm{CV}$ for $\mathrm{P}_{\text {dipeak }}$ at rest was $<7 \%$.

Plasma interleukin-6 concentration. For EX trial plasma IL-6 concentration data, three-way ANOVA with repeated measures across intervention (pre- vs. posttreatment) and time $(0,+1,+2$, and $+24 \mathrm{~h})$, with a between-subject factor of treatment (IMT vs. PLA), revealed a main effect of time $(P<$ $0.01)$ and intervention $(P=0.013)$ and a trend for an intervention $\times$ treatment interaction $(P=0.093)$ (Fig. 4). To explore the nature of this interaction subsequent, two-way ANOVA with repeated measures across time $(0,+1,+2$, and $+24 \mathrm{~h}$ ) and intervention (pre- vs. posttreatment) were performed separately for IMT and PLA groups and revealed that plasma IL-6 concentration was reduced after IMT (main effect of intervention, $P=0.039$ ), whereas there was no change after PLA $(P=0.272)$. For HYPEX trial plasma IL-6 concentration data, three-way ANOVA revealed a main effect of time $(P<$ 
Fig. 3. Peak transdiaphragmatic pressure $\left(\mathrm{P}_{\text {dipeak }} ; A\right)$, diaphragm pressure-time product $\left(\mathrm{PTP}_{\mathrm{di}} ; B\right)$, inspiratory muscle pressure-time product $\left(\mathrm{PTP}_{\mathrm{e}} ; C\right)$, and the relative contribution of diaphragm to the inspiratory muscle pressure-time product $\left(\mathrm{PTP}_{\mathrm{di}} / \mathrm{PTP}_{\mathrm{e}} ; D\right)$ for the PLA group. Values are means $\pm \mathrm{SD}$.

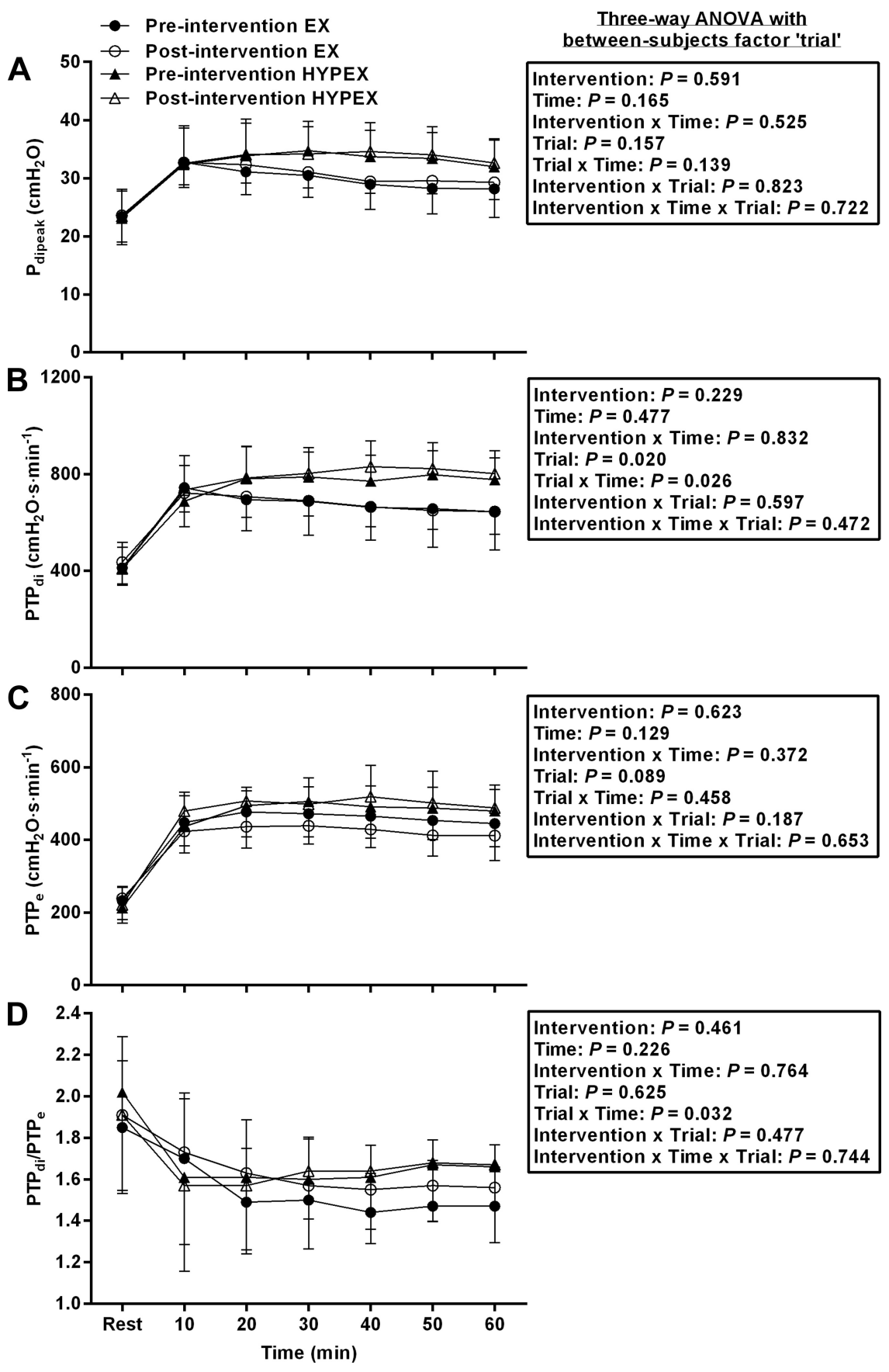

$0.01)$, but not for intervention $(P=0.306)$, and no intervention $\times$ treatment interaction $(P=0.304)$ (Fig. 4).

Blood lactate concentration, $\mathrm{pH}$, and $\mathrm{PCO}_{2}$. For $\mathrm{EX}$ trial data, three-way ANOVA with repeated measures across intervention (pre- vs. posttreatment) and time (10, 20, 30, 40, 50, and $60 \mathrm{~min}$ ), with a between-subject factor of treatment (PLA vs. IMT), revealed intervention $\times$ treatment interactions for $\left[\mathrm{La}^{-}\right]_{\mathrm{B}}(P=0.016)$ and $\mathrm{pH}(P=0.050)$ (Table 1$)$. To explore the nature of these interactions, subsequent two-way ANOVA with repeated measures across time $(10,20,30,40,50$, and 60 min) and intervention (pre- vs. posttreatment) were performed separately for IMT and PLA groups. After IMT, $\left[\mathrm{La}^{-}\right]_{\mathrm{B}}$ was reduced and $\mathrm{pH}$ was higher (main effects of intervention, $P<$
0.01), whereas $\left[\mathrm{La}^{-}\right]_{\mathrm{B}}$ and $\mathrm{pH}$ were unchanged after PLA. $\mathrm{PCO}_{2}$ during $\mathrm{EX}$ was unchanged postintervention (Table 1). During the preintervention HYPEX trial resting $\left[\mathrm{La}^{-}\right]_{\mathrm{B}}$ was $0.57 \pm 0.11$ and $0.76 \pm 0.12 \mathrm{mmol} / \mathrm{l}$ in IMT and PLA groups, respectively. A three-way ANOVA revealed that $\left[\mathrm{La}^{-}\right]_{\mathrm{B}}$ increased (main effect of time, $P=0.042$ ) and responses were unchanged postintervention (Table 1). There was no main effect of time for $\mathrm{pH}$ and $\mathrm{PCO}_{2}$ showing that these variables were maintained at rest during HYPEX (Table 1).

Twitch transdiaphragmatic pressures. A plateau (i.e., no significant increase in amplitude with increasing stimulation intensity) in $\mathrm{P}_{\text {ditw }}$ and $\mathrm{M}$-wave amplitude (data not shown) was observed in response to supramaximal BAMPS, indicating 


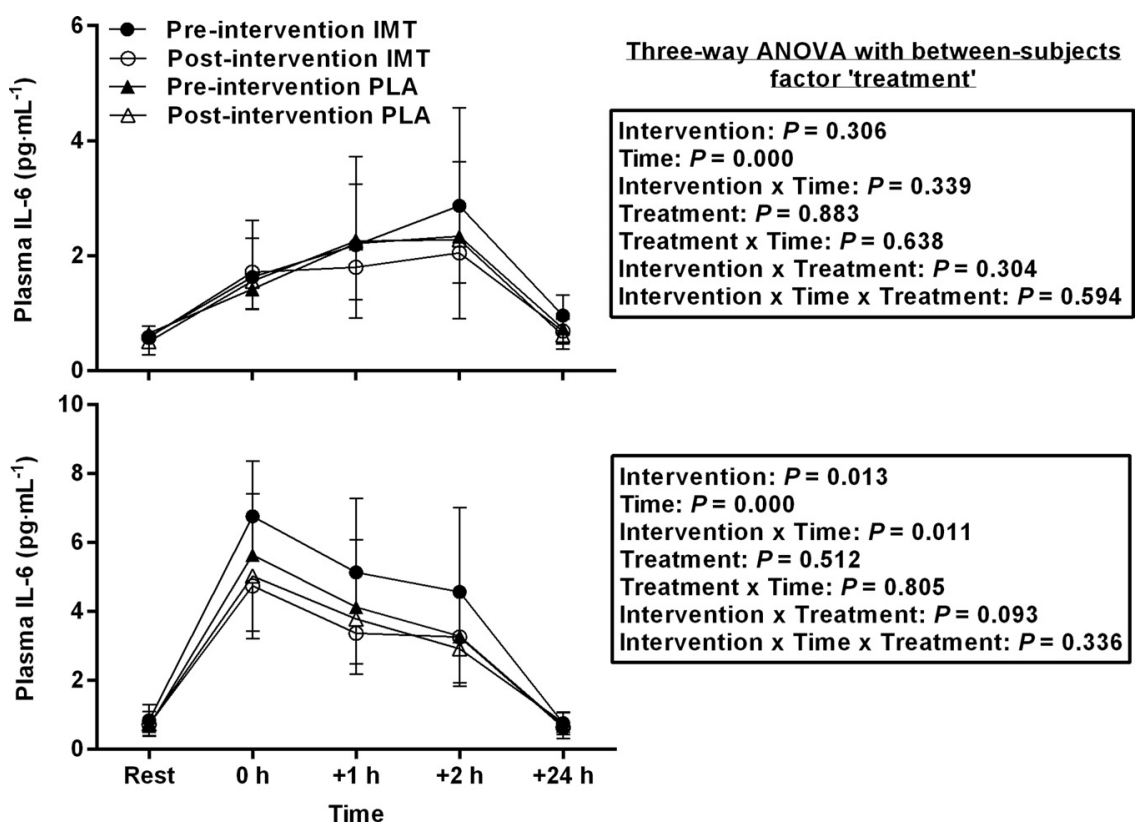

Fig. 4. Plasma interleukin-6 (IL-6) concentration for EX (bottom) and HYPEX (top) trials. Values are means $\pm \mathrm{SD}$. maximal depolarization of the phrenic nerves. Preintervention $\mathrm{P}_{\text {ditw }}$ and potentiated $\mathrm{P}_{\text {ditw }}$ for the IMT group were $15.6 \pm 5.1$ and $23.3 \pm 8.6 \mathrm{cmH}_{2} \mathrm{O}$ at baseline during $\mathrm{EX}$ and the inter- and intratrial $\mathrm{CV}$ for baseline $\mathrm{P}_{\text {ditw }}$ and potentiated $\mathrm{P}_{\text {ditw }}$ was $<8 \%$. Three-way ANOVA with repeated measures across intervention (pre- vs. posttreatment) and time (baseline, $<15,<35$, and $<60 \mathrm{~min}$ ), with a between-subject factor of treatment (PLA vs. IMT), revealed no main or interaction effects for $\mathrm{P}_{\text {ditw }}$ and potentiated $\mathrm{P}_{\text {ditw }}$ in either EX or HYPEX. Therefore there was no evidence of diaphragm fatigue following any trial.

Perceptual responses, cardiac frequency, and arterial oxygen saturation. For EX trial data, three-way ANOVA with repeated measures across intervention (pre- vs. posttreatment) and time $(10,20,30,40,50$, and $60 \mathrm{~min})$, with a betweensubject factor of treatment (PLA vs. IMT), revealed a main effect of intervention $(P=0.010)$ and an intervention $\times$ time $\times$ treatment interaction $(P=0.012)$ for RPE (dyspnea) (Table 1). To explore the nature of these findings, subsequent two-way ANOVA with repeated measures across time $(10,20$, $30,40,50$, and $60 \mathrm{~min}$ ) and intervention (pre- vs. posttreatment) were performed separately for IMT and PLA groups. RPE (dyspnea) was lower after IMT (main effects of intervention $P=0.006$ ) but unchanged after PLA. For HYPEX trial data, three-way ANOVA revealed an intervention $X$ treatment interaction $(P=0.024)$ for RPE (dyspnea) (Table 1). To explore the nature of this interaction, subsequent two-way ANOVA performed separately for IMT and PLA groups revealed a trend for RPE (dyspnea) to be lower after IMT (main effect of intervention, $P=0.054$ ) but not after PLA. Threeway ANOVA revealed no main or interaction effects for RPE (leg), $f_{\mathrm{C}}$, or $\mathrm{SpO}_{2}$ in EX or HYPEX trials (Table 1).

\section{DISCUSSION}

Main findings. The main findings of this study were that plasma IL-6 concentration increased following strenuous whole-body exercise (EX) and a volitional mimic of the breathing and respiratory muscle recruitment patterns achieved dur- ing EX (HYPEX) and that these increases occurred in the absence of diaphragm fatigue. In addition, the plasma IL-6 response to EX was attenuated following IMT.

To our knowledge, we are the first to report an increase in plasma IL-6 concentration following a volitional mimic of the exercise hyperpnea. The increase in IL-6 following HYPEX was of a similar magnitude to that reported following IRL at $75 \%$ MIP until task failure (64). However, our experimental model provides a more ecologically valid approach to assess whether the respiratory muscles release IL-6 during wholebody exercise. We are also confident that the increase in plasma IL-6 concentration observed during HYPEX is not an artifact of the experimental conditions since plasma IL-6 concentration was unchanged during the PASSIVE trial. Our data therefore suggest that the respiratory muscles do indeed contribute to the increase in plasma IL-6 concentration during whole body exercise.

Stimuli for interleukin-6. The stimuli responsible for the increase in plasma IL-6 concentration following HYPEX could not be established from the present study. We found no evidence of diaphragm fatigue following HYPEX, and confidence in our data is supported by the demonstration of supramaximal stimulation in $\mathrm{P}_{\text {ditw }}$ and $\mathrm{M}$-wave responses and excellent inter-/intratrial reliability in $\mathrm{P}_{\text {ditw }}$. Therefore our data do not support the notion $(63,64)$ that diaphragm fatigue triggers IL-6 release.

Oxidative stress due to enhanced generation of ROS and nitrogen species is an important regulator of IL-6 production. ROS can upregulate IL-6 in the diaphragms of rats exposed to IRL (54) and antioxidants can attenuate the plasma IL-6 response to IRL in humans (63). ROS are also upregulated by respiratory acidosis (3); however, we were careful to maintain $\mathrm{PCO}_{2}$ at resting levels. Upstream of ROS, nitric oxide production may be involved in the transcriptional signaling of IL-6 (57) and has been shown to regulate IL-6 production within the diaphragm of rats exposed to IRL (53). However, since muscle glycogen depletion during prolonged and strenuous lower- 
body exercise is a strong stimulus for enhanced IL- 6 production by skeletal muscle fibers $(34,56)$, a more likely mechanism for the production of IL-6 may be a reduction in respiratory muscle glycogen content. This notion is supported by the reduced diaphragm glycogen content of murines exposed to IRL (13) and whole-body exercise $(25,29)$.

Source of plasma interleukin-6. Contracting skeletal muscle accounts for most (but not all) of the increase in plasma IL-6 concentration observed during whole body exercise (58). Thus, although our experimental model did not allow the source(s) of the increased plasma IL-6 during HYPEX to be established, we attribute this increase to, primarily, increased IL-6 release from contracting respiratory muscles. This notion is consistent with the increased IL- 6 mRNA and protein expression in the diaphragm of rats exposed to IRL $(53,54,62)$, and the higher IL-6 protein expression in the external intercostals of COPD patients compared with healthy controls (12).

However, there may have been additional contributions from other sources to the increase in plasma IL-6 concentration during HYPEX. Excessive expiratory muscle contractions during HYPEX (as evidenced by a higher $\mathrm{PTP}_{\mathrm{di}}$ ), which has been previously observed in humans mimicking the pressure/flow characteristics of exercise hyperpnea (36), may have resulted in greater IL-6 release from expiratory muscles. The brain was also shown to release small amounts of IL-6 ( $\sim 60 \mathrm{pg} / \mathrm{min})$ following $60 \mathrm{~min}$ of cycling exercise (49). Furthermore, IL-6 may be upregulated within the lungs and subsequently enter the systemic circulation from permeation of epithelial and endothelial barriers with increased transmural pressures (61). This has been observed in murines exposed to negative or positive pressure ventilated hyperventilation (65) or IRL (60). However, this causes profound overdistension of the lung, which is unlikely during spontaneous hyperpnea in humans due to self-regulation of end-inspiratory and/or end-expiratory lung volumes.

When expressed relative to the size of the muscle group used, the arm muscles release greater amounts of IL-6 than leg muscles, and this is not directly related to release or uptake of exogenous substrate or muscle glycogen utilization (26). It may be possible that the respiratory muscles also contribute differently to systemic IL-6 release than other skeletal muscles due to differences in fiber type composition and vascular supply (48).

Effects of inspiratory muscle training on plasma interleukin-6 concentration. The present study is the first to demonstrate an attenuated plasma IL-6 response to whole-body exercise following IMT. Reduced IL- 6 production by inspiratory muscles following IMT may result from increases in basal levels of IL-6 receptor $\alpha(1,34)$ or antioxidant enzymes (70) or a reduction in muscle glycogen utilization $(16,22)$ secondary to training-induced increases in mitochondrial density (27). However, the decrease in plasma IL- 6 concentration during EX is unlikely to be explained by these changes alone as 1 ) plasma IL-6 concentration during HYPEX was not reduced and 2) the reduction in plasma IL-6 concentration during EX following IMT was greater than the increase observed during HYPEX. Thus alternate explanations may exist. First, when isolated diaphragmatic fibers are incubated with $\mathrm{CO}_{2}$ there is an increase in ROS (3). If ROS are a stimuli for IL-6 production, the increase in $\mathrm{pH}$ during EX (which did not occur in HYPEX) may have downregulated IL-6 production within the leg and/or respiratory muscles. Second, while supporting empirical evidence is not strong, respiratory muscle metaboreflex activation may be attenuated by IMT (66), thus promoting increased blood flow to the liver (21) and/or leg muscles (43). Increased blood flow to the liver may increase hepatosplanchnic uptake of IL-6 (21), whereas increased leg blood flow may result in less muscle glycogen utilization due to increased oxygen (5) and/or glucose (19) delivery.

Application to asthma and COPD. Asthma attacks and COPD exacerbations lead to systemic inflammation due to inflammatory cytokines. The local source of these cytokines is not, however, fully understood. Some suggest that cytokines spill out from the lungs into the systemic circulation, whereas others suggest that multiple organs contribute $(35,68)$. Consistent with previous studies $(11,63,64)$, our data suggest that the respiratory muscles directly contribute to the systemic inflammation observed in these patients when the work of breathing is increased. Furthermore, based on the findings of the present study, it is attractive to speculate that IMT may reduce the plasma IL-6 response during a period of increased respiratory muscle work in asthma and COPD patients.

Conclusion. In conclusion, plasma IL-6 concentration was increased, in the absence of diaphragm fatigue, following strenuous whole-body exercise (EX) and a volitional mimic of the exercise hyperpnea (HYPEX). Furthermore, the plasma IL-6 response to EX was attenuated following IMT. That the respiratory muscles may contribute to the increase in plasma IL-6 during whole body exercise raises several key questions: what other inflammatory cytokines are released from respiratory muscles during exercise and what are the key regulators of this IL-6 release? Are other cytokines increased/decreased following IMT and does this create a pro- or antiinflammatory response during exercise or volitional hyperpnea? What is the effect of IMT on the systemic inflammation observed in asthma and COPD patients?

\section{ACKNOWLEDGMENTS}

We acknowledge Dr. Rebecca Hill for her statistical support.

\section{DISCLOSURES}

No conflicts of interest, financial or otherwise, are declared by the author(s).

\section{AUTHOR CONTRIBUTIONS}

D.E.M., M.A.J., Y.A.B., and G.R.S. conception and design of research; D.E.M., M.A.J., M.J.M., N.C.W., J.T.G., and G.R.S. performed experiments; D.E.M. analyzed data; D.E.M., M.A.J., and G.R.S. interpreted results of experiments; D.E.M. prepared figures; D.E.M. drafted manuscript; D.E.M., M.A.J., Y.A.B., and G.R.S. edited and revised manuscript; D.E.M., M.A.J., Y.A.B., and G.R.S. approved final version of manuscript.

\section{REFERENCES}

1. Akerstrom TC, Krogh-Madsen R, Petersen AM, Pedersen BK. Glucose ingestion during endurance training in men attenuates expression of myokine receptor. Exp Physiol 94: 1124-1131, 2009.

2. American Thoracic Society/European Respiratory Society. ATS/ERS Statement on respiratory muscle testing. Am J Respir Crit Care Med 166: 518-624, 2002.

3. Arbogast S, Reid MB. Oxidant activity in skeletal muscle fibers is influenced by temperature, $\mathrm{CO} 2$ level, and muscle-derived nitric oxide. Am J Physiol Regul Integr Comp Physiol 287: R698-R705, 2004.

4. Babcock MA, Pegelow DF, McClaran SR, Suman OE, Dempsey JA. Contribution of diaphragmatic power output to exercise-induced diaphragm fatigue. J Appl Physiol 78: 1710-1719, 1995. 
5. Bailey SJ, Romer LM, Kelly J, Wilkerson DP, DiMenna FJ, Jones AM. Inspiratory muscle training enhances pulmonary $\mathrm{O}(2)$ uptake kinetics and high-intensity exercise tolerance in humans. J Appl Physiol 109: 457-468, 2010.

6. Borg GA. Psychophysical bases of perceived exertion. Med Sci Sports Exerc 14: 377-381, 1982.

7. Brown PI, Sharpe GR, Johnson MA. Inspiratory muscle training abolishes the blood lactate increase associated with volitional hyperpnoea superimposed on exercise and accelerates lactate and oxygen uptake kinetics at the onset of exercise. Eur J Appl Physiol 112: 2117-2129, 2012.

8. Brown PI, Sharpe GR, Johnson MA. Loading of trained inspiratory muscles speeds lactate recovery kinetics. Med Sci Sports Exerc 42: 1103-1112, 2010.

9. Brown PI, Sharpe GR, Johnson MA. Inspiratory muscle training reduces blood lactate concentration during volitional hyperpnoea. Eur $J$ Appl Physiol 104: 111-117, 2008.

10. Carey AL, Steinberg GR, Macaulay SL, Thomas WG, Holmes AG, Ramm G, Prelovsek O, Hohnen-Behrens C, Watt MJ, James DE, Kemp BE, Pedersen BK, Febbraio MA. Interleukin-6 increases insulinstimulated glucose disposal in humans and glucose uptake and fatty acid oxidation in vitro via AMP-activated protein kinase. Diabetes 55: $2688-$ 2697, 2006.

11. Casadevall C, Coronell C, Ausin P, Martinez-Llorens J, Orozco-Levi M, Barreiro E, Gea J, del Grupo E. NIGMA in COPD Inflammatory cytokines and repair factors in the intercostal muscles of patients with severe COPD. Arch Bronconeumol 45: 279-285, 2009.

12. Casadevall C, Coronell C, Ramirez-Sarmiento AL, Martinez-Llorens J, Barreiro E, Orozco-Levi M, Gea J. Upregulation of pro-inflammatory cytokines in the intercostal muscles of COPD patients. Eur Respir J 30: 701-707, 2007.

13. Ciufo R, Dimarco A, Stofan D, Nethery D, Supinski G. Dichloroacetate reduces diaphragmatic lactate formation but impairs respiratory performance. Am J Respir Crit Care Med 164: 1669-1674, 2001.

14. Clanton TL, Ameredes BT, Thomson DB, Julian MW. Sustainable inspiratory pressures over varying flows, volumes, and duty cycles. $J$ Appl Physiol 69: 1875-1882, 1990.

15. Clanton TL, Dixon GF, Drake J, Gadek JE. Effects of breathing pattern on inspiratory muscle endurance in humans. J Appl Physiol 59: 1834 $1841,1985$.

16. Croft L, Bartlett JD, MacLaren DP, Reilly T, Evans L, Mattey DL, Nixon NB, Drust B, Morton JP. High-intensity interval training attenuates the exercise-induced increase in plasma IL-6 in response to acute exercise. Appl Physiol Nutr Metab 34: 1098-1107, 2009.

17. Davies CT, White MJ. Muscle weakness following dynamic exercise in humans. J Appl Physiol 53: 236-241, 1982.

18. Eastwood PR, Hillman DR, Finucane KE. Ventilatory responses to inspiratory threshold loading and role of muscle fatigue in task failure. $J$ Appl Physiol 76: 185-195, 1994.

19. Ebeling P, Bourey R, Koranyi L, Tuominen JA, Groop LC, Henriksson J, Mueckler M, Sovijarvi A, Koivisto VA. Mechanism of enhanced insulin sensitivity in athletes: Increased blood flow, muscle glucose transport protein (GLUT-4) concentration, and glycogen synthase activity. J Clin Invest 92: 1623-1631, 1993.

20. Febbraio MA, Hiscock N, Sacchetti M, Fischer CP, Pedersen BK. Interleukin-6 is a novel factor mediating glucose homeostasis during skeletal muscle contraction. Diabetes 53: 1643-1648, 2004.

21. Febbraio MA, Ott P, Nielsen HB, Steensberg A, Keller C, Krustrup P, Secher NH, Pedersen BK. Hepatosplanchnic clearance of interleukin-6 in humans during exercise. Am J Physiol Endocrinol Metab 285: E397E402, 2003.

22. Fischer CP, Plomgaard P, Hansen AK, Pilegaard H, Saltin B, Pedersen BK. Endurance training reduces the contraction-induced interleukin-6 mRNA expression in human skeletal muscle. Am J Physiol Endocrinol Metab 287: E1189-E1194, 2004.

23. Freedman S, Cooke NT, Moxham J. Production of lactic acid by respiratory muscles. Thorax 38: 50-54, 1983.

24. Glerant JC, Mustfa N, Man WD, Luo YM, Rafferty G, Polkey MI, Moxham J. Diaphragm electromyograms recorded from multiple surface electrodes following magnetic stimulation. Eur Respir J 27: 334-342, 2006.

25. Green HJ, Ball-Burnett ME, Morrissey MA, Spalding MJ, Hughson RL, Fraser IG. Fiber type specific glycogen utilization in rat diaphragm during treadmill exercise. $J$ Appl Physiol 63: 75-83, 1987.
26. Helge JW, Klein DK, Andersen TM, van Hall G, Calbet J, Boushel R, Saltin B. Interleukin-6 release is higher across arm than leg muscles during whole-body exercise. Exp Physiol 96: 590-598, 2011.

27. Hoppeler H, Fluck M. Plasticity of skeletal muscle mitochondria: Structure and function. Med Sci Sports Exerc 35: 95-104, 2003.

28. Hubmayr RD, Litchy WJ, Gay PC, Nelson SB. Transdiaphragmatic twitch pressure: Effects of lung volume and chest wall shape. Am Rev Respir Dis 139: 647-652, 1989.

29. Ianuzzo CD, Spalding MJ, Williams H. Exercise-induced glycogen utilization by the respiratory muscles. J Appl Physiol 62: 1405-1409, 1987.

30. Izquierdo M, Ibanez J, Calbet JA, Navarro-Amezqueta I, GonzalezIzal M, Idoate F, Hakkinen K, Kraemer WJ, Palacios-Sarrasqueta M, Almar M, Gorostiaga EM. Cytokine and hormone responses to resistance training. Eur J Appl Physiol 107: 397-409, 2009.

31. Johnson MA, Mills DE, Brown DM, Bayfield KJ, Gonzalez JT, Sharpe GR. Inspiratory loading intensity does not influence lactate clearance during recovery. Med Sci Sports Exerc 44: 863-871, 2012.

32. Johnson MA, Sharpe GR, Brown PI. Investigations of the lactate minimum test. Int J Sports Med 30: 448-454, 2009.

33. Johnson MA, Sharpe GR, McConnell AK. Maximal voluntary hyperpnoea increases blood lactate concentration during exercise. Eur J Appl Physiol 96: 600-608, 2006.

34. Keller C, Steensberg A, Hansen AK, Fischer CP, Plomgaard P, Pedersen BK. Effect of exercise, training, and glycogen availability on IL-6 receptor expression in human skeletal muscle. J Appl Physiol 99: 2075-2079, 2005.

35. Kirkham P, Rahman I. Oxidative stress in asthma and COPD: Antioxidants as a therapeutic strategy. Pharmacol Ther 111: 476-494, 2006.

36. Klas JV, Dempsey JA. Voluntary versus reflex regulation of maximal exercise flow: Volume loops. Am Rev Respir Dis 139: 150-156, 1989.

37. Koulouris N, Mulvey DA, Laroche CM, Goldstone J, Moxham J, Green M. The effect of posture and abdominal binding on respiratory pressures. Eur Respir J 2: 961-965, 1989.

38. Kufel TJ, Pineda LA, Junega RG, Hathwar R, Mador MJ. Diaphragmatic function after intense exercise in congestive heart failure patients Eur Respir J 20: 1399-1405, 2002.

39. Laghi F, D'Alfonso N, Tobin MJ. Pattern of recovery from diaphragmatic fatigue over 24 hours. J Appl Physiol 79: 539-546, 1995.

40. Laghi F, Topeli A, Tobin MJ. Does resistive loading decrease diaphragmatic contractility before task failure? J Appl Physiol 85: 1103-1112, 1998.

41. Mador MJ, Magalang UJ, Kufel TJ. Twitch potentiation following voluntary diaphragmatic contraction. Am J Respir Crit Care Med 149: 739-743, 1994.

42. Man WD, Luo YM, Mustfa N, Rafferty GF, Glerant JC, Polkey MI, Moxham J. Postprandial effects on twitch transdiaphragmatic pressure. Eur Respir J 20: 577-580, 2002.

43. McConnell AK, Lomax M. The influence of inspiratory muscle work history and specific inspiratory muscle training upon human limb muscle fatigue. J Physiol 557: 445-457, 2006.

44. McKenzie DK, Allen GM, Butler JE, Gandevia SC. Task failure with lack of diaphragm fatigue during inspiratory resistive loading in human subjects. J Appl Physiol 82: 2011-2019, 1997.

45. McLoughlin P, Popham P, Linton RA, Bruce RC, Band DM. Use of arterialized venous blood sampling during incremental exercise tests. $J$ Appl Physiol 73: 937-940, 1992.

46. Miller MR, Hankinson J, Brusasco V, Burgos F, Casaburi R, Coates A, Crapo R, Enright P, van der Grinten CP, Gustafsson P, Jensen R, Johnson DC, MacIntyre N, McKay R, Navajas D, Pedersen OF, Pellegrino R, Viegi G, Wanger J, ATS Task Force/ERS. Standardisation of spirometry. Eur Respir J 26: 319-338, 2005.

47. Mills GH, Kyroussis D, Hamnegard CH, Polkey MI, Green M, Moxham J. Bilateral magnetic stimulation of the phrenic nerves from an anterolateral approach. Am J Respir Crit Care Med 154: 1099-1105, 1996.

48. Mizuno M. Human respiratory muscles: Fibre morphology and capillary supply. Eur Respir J 4: 587-601, 1991.

49. Nybo L, Nielsen B, Pedersen BK, Moller K, Secher NH. Interleukin-6 release from the human brain during prolonged exercise. J Physiol 542: 991-995, 2002

50. Pedersen BK, Febbraio MA. Muscle as an endocrine organ: Focus on muscle-derived interleukin-6. Physiol Rev 88: 1379-1406, 2008. 
51. Ramirez-Sarmiento A, Orozco-Levi M, Guell R, Barreiro E, Hernandez N, Mota S, Sangenis M, Broquetas JM, Casan P, Gea J. Inspiratory muscle training in patients with chronic obstructive pulmonary disease: Structural adaptation and physiologic outcomes. Am J Respir Crit Care Med 166: 1491-1497, 2002

52. Romer LM, McConnell AK. Specificity and reversibility of inspiratory muscle training. Med Sci Sports Exerc 35: 237-244, 2003.

53. Sigala I, Zacharatos P, Boulia S, Toumpanakis D, Michailidou T, Parthenis D, Roussos C, Papapetropoulos A, Hussain SN, Vassilakopoulos $\mathbf{T}$. Nitric oxide regulates cytokine induction in the diaphragm in response to inspiratory resistive breathing. J Appl Physiol 113: $1594-$ 1603, 2012.

54. Sigala I, Zacharatos $\mathbf{P}$, Toumpanakis D, Michailidou T, Noussia $\mathbf{O}$, Theocharis S, Roussos C, Papapetropoulos A, Vassilakopoulos T. MAPKs and NF-kappaB differentially regulate cytokine expression in the diaphragm in response to resistive breathing: the role of oxidative stress. Am J Physiol Regul Integr Comp Physiol 300: R1152-R1162, 2011.

55. Smith J, Bellemare F. Effect of lung volume on in vivo contraction characteristics of human diaphragm. J Appl Physiol 62: 1893-1900, 1987.

56. Steensberg A, Febbraio MA, Osada T, Schjerling P, van Hall G, Saltin B, Pedersen BK. Interleukin-6 production in contracting human skeletal muscle is influenced by preexercise muscle glycogen content. $J$ Physiol 537: 633-639, 2001.

57. Steensberg A, Keller C, Hillig T, Frosig C, Wojtaszewski JF, Pedersen BK, Pilegaard H, Sander M. Nitric oxide production is a proximal signaling event controlling exercise-induced mRNA expression in human skeletal muscle. FASEB J 21: 2683-2694, 2007.

58. Steensberg A, van Hall G, Osada T, Sacchetti M, Saltin B, Klarlund Pedersen B. Production of interleukin-6 in contracting human skeletal muscles can account for the exercise-induced increase in plasma interleukin-6. J Physiol 529: 237-242, 2000.

59. Taylor JL, Butler JE, Allen GM, Gandevia SC. Changes in motor cortical excitability during human muscle fatigue. J Physiol 490: 519528,1996

60. Toumpanakis D, Kastis GA, Zacharatos P, Sigala I, Michailidou T, Kouvela M, Glynos C, Divangahi M, Roussos C, Theocharis SE,
Vassilakopoulos T. Inspiratory resistive breathing induces acute lung injury. Am J Respir Crit Care Med 182: 1129-1136, 2010.

61. Uhlig S. Ventilation-induced lung injury and mechanotransduction: stretching it too far? Am J Physiol Lung Cell Mol Physiol 282: L892L896, 2002.

62. Vassilakopoulos T, Divangahi M, Rallis G, Kishta O, Petrof B, Comtois A, Hussain SN. Differential cytokine gene expression in the diaphragm in response to strenuous resistive breathing. Am J Respir Crit Care Med 170: 154-161, 2004.

63. Vassilakopoulos T, Katsaounou P, Karatza MH, Kollintza A, Zakynthinos S, Roussos C. Strenuous resistive breathing induces plasma cytokines: Role of antioxidants and monocytes. Am J Respir Crit Care Med 166: 1572-1578, 2002.

64. Vassilakopoulos T, Zakynthinos S, Roussos C. Strenuous resistive breathing induces proinflammatory cytokines and stimulates the HPA axis in humans. Am J Physiol Regul Integr Comp Physiol 277: R1013-R1019, 1999.

65. von Bethmann AN, Brasch F, Nusing R, Vogt K, Volk HD, Muller KM, Wendel A, Uhlig S. Hyperventilation induces release of cytokines from perfused mouse lung. Am J Respir Crit Care Med 157: 263-272, 1998.

66. Witt JD, Guenette JA, Rupert JL, McKenzie DC, Sheel AW. Inspiratory muscle training attenuates the human respiratory muscle metaboreflex. J Physiol 584: 1019-1028, 2007.

67. Wolsk E, Mygind H, Grondahl TS, Pedersen BK, van Hall G. IL-6 selectively stimulates fat metabolism in human skeletal muscle. Am J Physiol Endocrinol Metab 299: E832-E840, 2010.

68. Wouters EF, Reynaert NL, Dentener MA, Vernooy JH. Systemic and local inflammation in asthma and chronic obstructive pulmonary disease: Is there a connection? Proc Am Thorac Soc 6: 638-647, 2009.

69. Wragg S, Hamnegard C, Road J, Kyroussis D, Moran J, Green M, Moxham J. Potentiation of diaphragmatic twitch after voluntary contraction in normal subjects. Thorax 49: 1234-1237, 1994.

70. Yfanti C, Fischer CP, Nielsen S, Akerstrom T, Nielsen AR, Veskoukis AS, Kouretas D, Lykkesfeldt J, Pilegaard H, Pedersen BK. Role of vitamin $\mathrm{C}$ and $\mathrm{E}$ supplementation on IL-6 in response to training. $J$ Appl Physiol 112: 990-1000, 2012. 